ophthalmological interest in connection with public aftairs. $\mathrm{Mr}$. E.Treacher Collins, president of the Ophthalmological Society of the United Kingdom, was voted to the chair. The resolution that such a council (see these columns April, 1918, p. 230) be formed was proposed by Sir Anderson Critchett, Bt., C.V.O., who said it would meet a definite need, would tend to weld the elements of ophthalmology more closely together, and would make for the public welfare. Mr. F. Richardson Cross seconded the resolution, remarking that governments and governing bodies required expert advice in order to be efficient, and that the best experts were those who enjoyed the confidence of their colleagues. Owing to the amalgamation of the journals devoted to ophthalmology, and to the representation on the Ophthalmological Society of the various similar bodies in the kingdom, the profession was now well organized, and could present a powerful front on all questions which specially concerned it. As instances he mentioned ophthalmia neonatorum, Army and Navy visual standards, industrial lighting, enquiries concerning the blind, compensation payable according to degrees of visual disability, and so forth. Mr. J. B. Lawford, in supporting the resolution, said that the days were rapidly passing when we could afiord to ignore scientific discoveries and the new methods based upon them, and he believed that in the future more attention would be paid to the views of representative bodies and less to the opinions of individuals, however eminent. The State was assuming more and more the rôle of parent, and, like other parents, would be the better for sound advice. He would like to see ophthalmology made a compulsory subject in the medical curriculum, a matter in which we were much behind other civilized countries. At present a man who obtained the minimal qualifying medical diploma could at once take up the practice of ophthalmology, and if the council did nothing beyond insisting that it was not taken up without special training, it would fully justify its formation. Speeches in support were made by Mr. J. Gray Clegg, Sir George Berry, and Mr. George Mackay, and the resolution was carried unanimously. The meeting further decided that the council should consist of all the past and present presidents of the Ophthalmological Society of the United Kingdom and of the Section of Ophthalmology of the Royal Society of Medicine (permanent members), of four members nominated annually by the councils of each of those societies, and of one representative, also elected annually, by the Oxford Ophthalmological Congress.

\title{
Medical Certificates
}

A circular dated March 12, 1918, dealing with medical certificates in connection with men who appear before National Service Medical 
Boards, has been issued to members of the medical profession by the Minister of National Service. The memorandum has not appeared a day too soon. It points out that a properly drawn certificate may be of great assistance to a Board, and that such a document is sure to receive full consideration. A good certificate should state name, age, and address of patient; date of last personal examination; length of time the patient has been personally known to the certifier; what diseases the latter has attended him for; the patient's present physical condition; and the name, address, and qualifications of the certifier. Particular care should be taken to avoid any expression of opinion as to the man's fitness or unfitness. for Military Service, which is a matter for the Board to form an opinion upon. Thus, it is one thing to certify that a man's sight is $1 / 10$ normal, and quite another to state that he is thereby unfitted for Service. A good certificate confines itself to matters which have come under the practitioner's personal knowledge. If reference be made to other matters not within the certifier's cognizance that fact should be made plain. For example, a certificate of epilepsy may be given, although the practitioner has never seen the patient in or immediately after an epileptic fit. The statement, in fact, is based upon nothing stronger than the man's word that he is subject to convulsive seizures. To put the matter briefly, a medical man who is called upon to give a certificate should regard himself as an impartial witness and not as an advocate or a judge.

\section{Eyelashes in the Anterior Chamber}

The Lancet (January 19, 1918) comments on an article by Cantonnet in the Progrès Médical (date not given) referring to the presence of eyelashes in the anterior chamber as a war injury, and gives the details of diagnosis and surgical treatment. Apparently Cantonnet is referring to cases in which the lashes have found their way into the chamber as the result of an explosion of a projectile, but without a definite wound. "It is difficult to understand" says the Lancet, " how a body so supple, long, and light as an eyelash can be torn from the eyelid and driven through the cornea to the iris. If at the same time a lesion, such as traumatic cataract, is produced, indicating the entrance to the eye of a comparatively large body, it is easy to imagine that in its passage it may have detached an eyelash and carried this with it. But when there are only punctiform specks on the cornea, without proof of any penetration, it is difficult to understand how the lashes can have penetrated." We are not so sceptical as our contemporary seems to be, but all the same this is an interesting subject on which we do 